\title{
DETECTION OF A VOLCANIC AQUIFER BY TDEM SOUNDINGS
}

\author{
GIUSEPPE PAGANO, ANTONIO MENGHINI, STEFANO FLORIS
}

\author{
S.Te.G.A., Via Monte Bianco 5, 01100 VITERBO (ITALY) - Fax +39 761228191
}

The purpose of this presentation is to show the great power of resolution of Time Domain Electromagnetics Methods in volcanics areas, in comparison with classic electric methods.

We performed a hydrogeological study aimed to water supply, in an area laying to the north-east of Bolsena Lake, the largest Italian volcanic lake. The schematic geological succession is represented by volcanics of the Vulsini apparatus (tuffs, lavas and scoriae), resting on a sedimentary substratum (clays and turbidites). Volcanics represent the main regional aquifer, thanks to good porosity and fracturation of rocks, while sedimentary substratum is impermeable, so that it constitutes the aquiclude. Volcanic aquifer feeds Bolsena Lake and some important springs. The structural characters of sedimentary substratum strongly determine underground drainage: the most productive areas are located above "structural low" (where impermeable substratum is deeper), thanks to the greater thickness of the aquifer.

Geophysical methods are very useful to detect the most promising hydrogeological areas; in fact the volcanic aquifer is more resistive than sedimentary substratum, so it is possible to reconstruct the geometry of the aquiclude top. For this reason electrical methods has been widely used for hydrogeological investigations; but sometimes these methods provided poor results: a well excavated on the ground of a previous geophysical survey, showed poor productivity. This is due to the fact that electric soundings are not always able to resolve aquiclude; other geophysicists interpreted the conductive layer, which lays under a resistive unit, as the impermeable substratum, but they openly forced geophysical data: it is too much optimistic to interpret the maximum of the curve, placed at about $A B=1000 \mathrm{~m}$, as the top of the sedimentary substratum; according to this model, the aquiclude should be rest at a depth of about $400 \mathrm{~m}$, which is clearly an overestimated depth of exploration for SEV.

Our SEV also show a maximum at $A B=400-500 \mathrm{~m}$ (see Fig.1), but a more realistic interpretation detects a conductive layer at a depth of about $130 \mathrm{~m}$; it is cannot be the aquiclude, because it is too much shallow. The same conductive layer is detected by TDEM 
soundings, but they are able to resolve another deeper conductive formation, resting at a depth consistent with the structural maps of the area, which was reconstructed by deep drill-holes. Fig. 2 shows a TDEM sounding performed by EM57 transmitter, Protem receiver, square loop $100 \times 100 \mathrm{~m}$ (all instrumentation by Geonics Ltd.); the first conductive layer lies at a depth of about $150 \mathrm{~m}$, while the sedimentary substratum is defined by the deeper conductive layer which rests at a depth of about $380 \mathrm{~m}$.

A calibration test performed close to a known well (Fig.3), confirms the conductive behaviour of the aquiclude ( $\mathrm{rho}=8 \mathrm{ohm} \mathrm{xm}$ ), while the first conductive layer is referable to the saturated portion of volcanics ( $r$ ho $=27 \mathrm{ohm} \mathrm{x} \mathrm{m}$ ). In other words the shallow conductive unit represents the volcanic aquifer, so by TDEM soundings it is possible to map the geometry and the thickness of the hydrogeological unit. The top of the first conductive layer shows a geometry very similar to that of isophreatic lines, as it gently dips towards south-west, in the direction of Bolsena Lake.

We elaborated a strucural map of the top of sedimentary substratum, so that to locate the "structural lows" which interest hydrogeological survey; then we reconstructed an isopachs map of the aquifer which confirms the results of the previous map. It is possible to detect a maximum depth of the aquiclude at about $300-370 \mathrm{~m}$, together with a maximum thickness of the volcanic aquifer (about $200 \mathrm{~m}$ ).

Conductance, the product of conductivity and the thickness of the stratum, is a geophysical quantity which can be closely connected to hydraulic transmissivity; the maximum of conductance (over 16 Siemens) is located above the main structural low.

A well was drilled in this point; it is $227 \mathrm{~m}$ depth and it did not reach the aquiclude; according to geophysical data, it should be place at a depth of about $370 \mathrm{~m}$. The well drilled tuffs, massive and fractured lavas, alternate layers of tuffs, lavas and scoriae; the first water manifestations happened at a depth of $127 \mathrm{~m}$, but it represents a shallow aquifer. The most productive aquifer is placed at a depth of about $170 \mathrm{~m}$ and it interests a formation of alternate tuffs, lavas and scoriae. This is the first conductive layer (14-16 ohm x m) which was resolved by TDEM sounding at a depth of about $160 \mathrm{~m}$. The following pumping tests confirm this hydrogeological situations. They show also a good transmissivity of the aquifer $(\mathrm{T}=0,0097$ $\mathrm{mq} / \mathrm{sec})$ and a considerable capacity of the well $(\mathrm{Q}=28 \mathrm{l} / \mathrm{sec})$. 


\section{REFERENCES}

FITTERMAN D.V. and STEWART M.T. (1986) - Transient electromagnetic sounding for groundwater - Geophysics vol.51

KAUFMAN A.A. and KELLER G.V. (1983) - Frequency and transient soundings - Elsevier Science Publ.

McNEILL J.D. (1980) - Electrical conductivity of soil and rocks - Technical Note TN-5

Geonics Limited

McNEILL J.D. (1980) - Application of transient electromagnetic techniques - Technical Note TN-7 Geonics Limited

McNEILL J.D. (1990) - Use of electromagnetic methods for groundwater studies Investigations in Geophysics n.5 S.E.G.

NABIGHIAN M.N. (1991) - Electromagnetic methods in applied Geophysics Vol. 1 e 2 Investigations in Geophysics n.3 S.E.G.

RAICHE A.P., JUPP D.L.B., RUTTER H. and VOZOFF K. (1985) - The joint use of coincident loop transient electromagnetic and Schlumberger sounding to resolve layered structures - Geophysics vol.50

SPIES B.R. and EGGERS D.E. (1986) - The use and misuse of apparent resistivity in electromagnetic methods - Geophysics vol.51

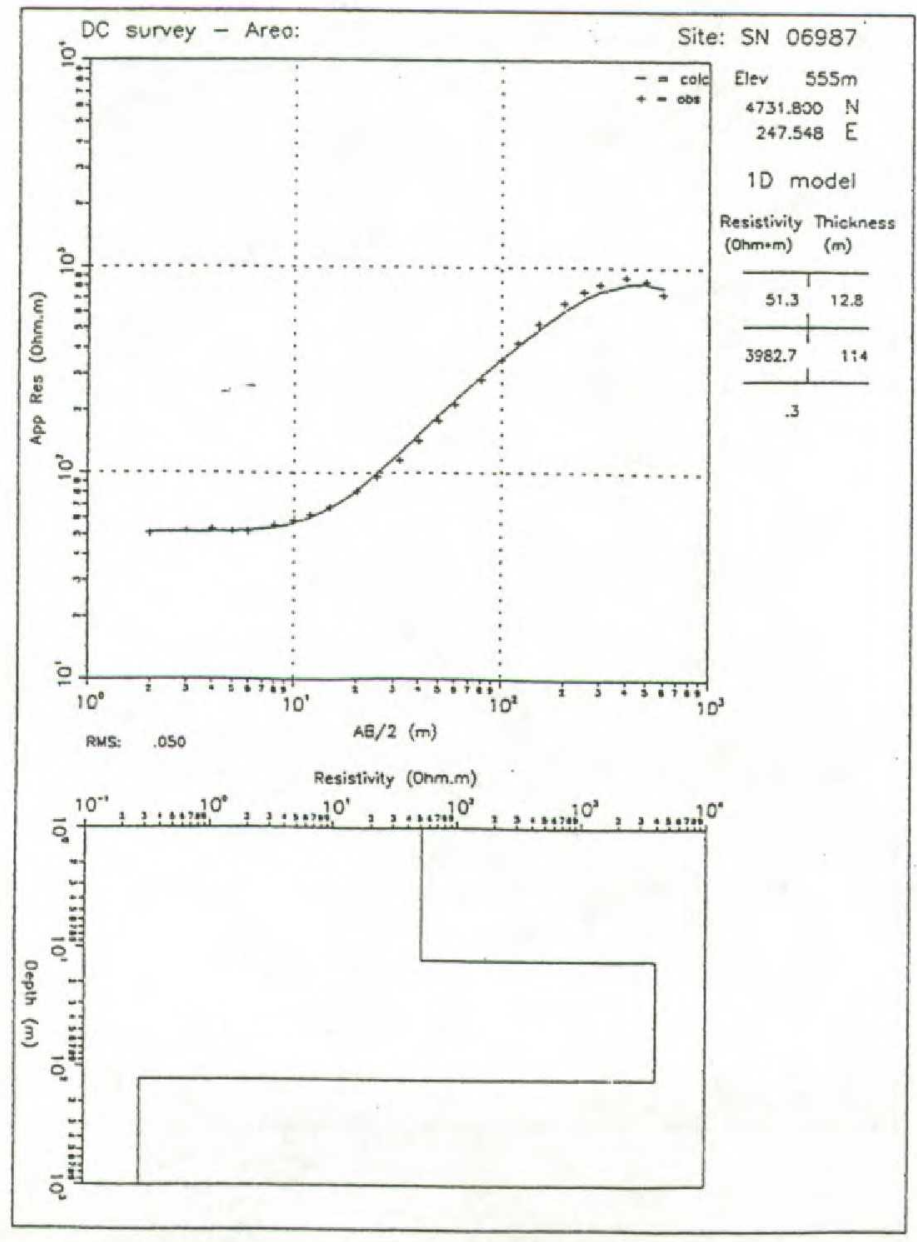

\section{FIG.1}



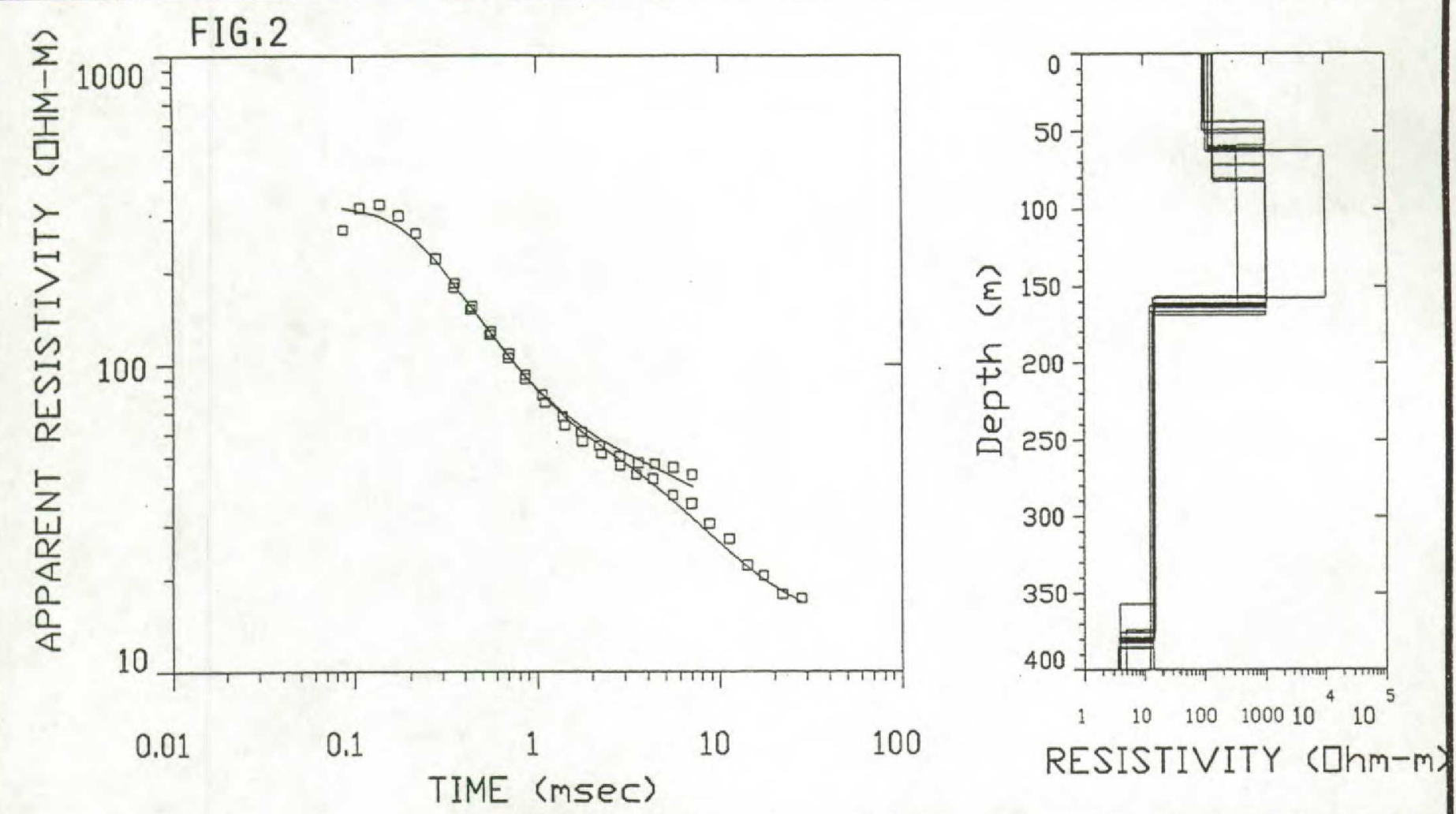

\begin{tabular}{|c|c|c|}
\hline \multicolumn{2}{|c|}{ for: $C_{1} A_{1} A_{1} V_{1}$} & STUDID IDRDGETLGGICD \\
\hline by $\quad \mathrm{S} . \mathrm{Te}$. & G.A. & C.PDGGID LASCA \\
\hline Dota Set: BTORRDNE & Date: $21 / 03 / 95$ & CASTEL GIDRGID ( $T$ \\
\hline Equpenent & Sounding: 8 & LQQP \\
\hline
\end{tabular}
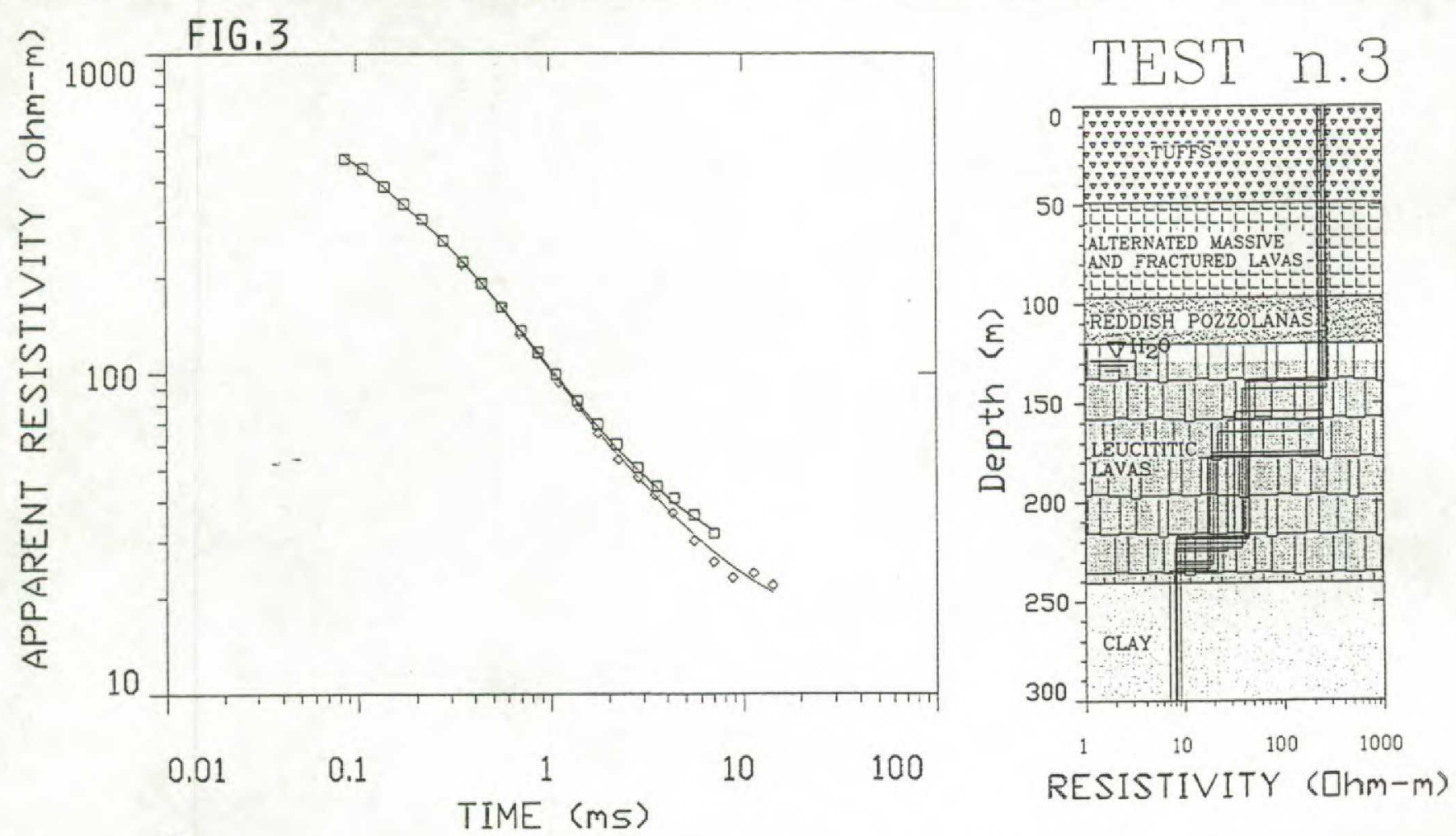

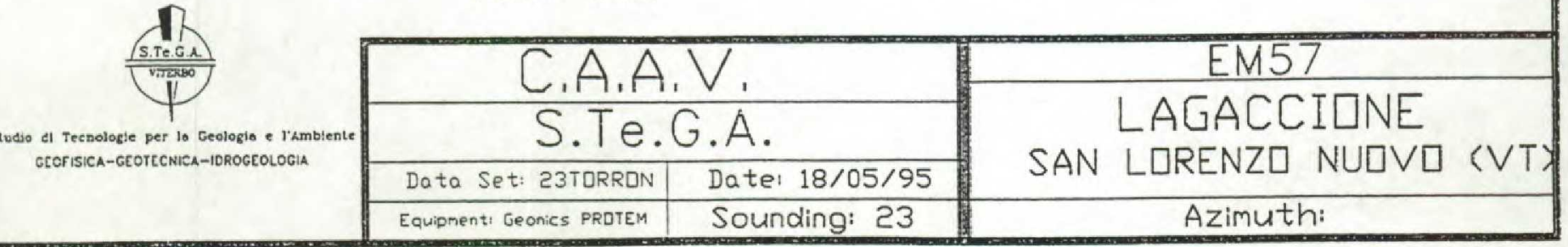

